\title{
Treating chronic periodontitis: current status, challenges, and future directions
}

This article was published in the following Dove Press journal:

Clinical, Cosmetic and Investigational Dentistry

4 August 2010

Number of times this article has been viewed

\author{
Luciana M Shaddox ${ }^{1,2}$ \\ Clay B Walker ${ }^{2}$
}

Departments of 'Periodontology, ${ }^{2}$ Department Oral Biology, University of Florida, Gainesville, FL, USA
Correspondence: Luciana M Shaddox Department of Periodontics, University of Florida, PO Box 100434, Gainesville, FL 32610-0407, USA

Tel +l 3522738368

Fax +I 3523925899

Email Ishaddox@dental.ufl.edu
Abstract: Periodontitis affects roughly one-third of the US population. A timely diagnosis of chronic periodontitis at its earliest stage is essential to avoid more challenging severe stages of the disease. Most cases of slight and moderate chronic periodontitis can be successfully managed by mechanical removal and/or reduction of subgingival bacterial biofilms and calculus. However, any factor that affects either the local environment or the host response may contribute to progression of the disease and a poor treatment response. Thus, it is essential that clinicians are aware of etiologic and risk factors associated with disease development and progression in order to plan and execute a successful treatment. This paper reviews a variety of risk factors, both local and systemic, that can impact the successful treatment of chronic periodontitis.

Keywords: periodontal disease, gingivitis, treatment, risk factors

\section{Introduction}

Periodontal disease is an inflammatory process that affects the protective and supportive tissues around the tooth. Bacterial plaque accumulation on the tooth surface leads to marginal tissue inflammation, known as gingivitis. Gingivitis is fairly common and is present in up to $90 \%$ of the US population. ${ }^{1}$ If left untreated, gingivitis may progress to periodontitis, which is characterized by loss of periodontal attachment support (clinical attachment loss, $[\mathrm{CAL}]$ ) and bone resorption, eventually resulting in tooth mobility and loss. Chronic periodontitis is a common disease characterized by a painless, slow progression. It may occur in most age groups, but is most prevalent among adults and seniors worldwide, with approximately $35 \%$ of adults (30-90 years) in the US being affected by at least one site with $\mathrm{CAL} \geq 3 \mathrm{~mm}$ and probing depth (PD) $\geq 4 \mathrm{~mm}{ }^{2}$

The first challenge in treating periodontitis is a timely and proper diagnosis. Disease diagnosis and treatment in its earliest stages will prevent future breakdown. Because the disease is painless, patients rarely seek care. Thus, it is not uncommon for the disease to go undiagnosed until progression has reached moderate to advanced degrees of severity, characterized by obvious radiographic bone loss and/or tooth mobility.

The second challenge is diagnosing and properly controlling all the factors contributing to this disease. The primary etiology for periodontal diseases is bacteria, which can cause direct and indirect destruction of the host supporting tissues. In fact, most cases of chronic periodontitis are successfully managed by mechanical removal/ reduction of bacterial mass and calculus in the subgingival environment by scaling and root planing. ${ }^{3-6}$ However, any factor that influences either the local environment or the host response may contribute to disease progression and response to treatment. Such factors include smoking, diabetes, stress, genetic factors, occlusal trauma, iatrogenic 
dentistry, and patient compliance. Due to its numerous and complex contributing factors, successful management of chronic periodontitis can be very challenging. Thus, it is imperative that clinicians are aware of risk factors contributing to the patient's susceptibility to disease, response to existing disease, and potential response to therapy before initiating a treatment plan.

The third challenge in the treatment of chronic periodontitis involves the long-term maintenance of the periodontium. This phase of therapy is known as supportive periodontal therapy, or periodontal maintenance. The challenge during this phase of therapy is focused on maintaining patient motivation and compliance, management of all risk factors, and finally making the appropriate decisions regarding retreatment, when indicated.

This paper aims to provide the clinician with current information on a variety of local and systemic risk factors that must be addressed in order to provide the best possible outcome when faced with the challenges of treating chronic periodontitis.

\section{Diagnosis of chronic periodontitis}

Chronic periodontitis is more prevalent than the general population recognizes. Around $80 \%$ of adults in the US have at least one site with attachment loss. More severe chronic periodontitis affects roughly $35 \%$ of the US population. ${ }^{1,2}$ Interestingly, only a small percentage of this population seek periodontal care. This becomes the first challenge of treating periodontitis.

Generally, chronic periodontitis is not the chief complaint of a patient when he/she seeks dental treatment. The reason is that chronic periodontitis usually progresses painlessly and slowly. A study reported that the most common chief complaint reported by chronic periodontitis subjects is: "I was told I have gum disease". The second most common chief complaint reported is: "I would like to save my teeth". Neither of these chief complaints are true chronic periodontitis symptoms, such as bleeding gums. Only $6.2 \%$ of the subjects reported having painful gingiva. ${ }^{7}$ Thus, most diagnosis of this condition occurs when the disease reaches a severe stage where clinically detectable mobility and radiographic bone loss is evident.

Different methods for diagnosing chronic periodontitis exist. Periodontal screening and recording was devised by the American Dental Association and American Academy of Periodontotology to facilitate early detection of periodontal disease with a simplified probing technique and minimum documentation. ${ }^{8}$ This method is still largely used by general dentists during initial disease screening. It has shown correlation with the traditional method of complete periodontal examination, however, it can potentially underestimate the presence of periodontal disease. ${ }^{8}$ Thus, a full-mouth examination and recording is preferred so that initial stages of periodontal disease can be detected and treated.

A complete examination should include PD, CAL, bleeding on probing (BOP), plaque index/score, furcation involvement, suppuration, mobility, occlusal trauma, open contact areas, and radiographic interpretation of bone levels. A combined evaluation of these parameters is essential for a proper periodontal evaluation and diagnosis. Without these measures, it is difficult to establish a proper diagnosis and therefore, proper treatment of the patient.

Radiographic interpretation is an important adjunct to periodontal probing to differentiate between true attachment loss versus gingival edema/gingivitis. However, conventional radiographs routinely underestimate the amount of bone loss. ${ }^{9}$ In addition, sequentially taken radiographs, when examined by eye, are able to reveal changes in bone only after $30 \%-50 \%$ of the bone mineral has been resorbed..$^{10}$ Thus, disease diagnosis should include both a very thorough periodontal examination in addition to careful radiographic evaluation to determine early stages of chronic periodontitis.

The clinician should keep in mind that not every case of gingivitis progresses to chronic periodontitis, but every chronic periodontitis progresses from gingivitis. Thus, the first step in preventing attachment loss is to control gingival inflammation. The diagnosis of chronic periodontitis at earlier stages would enable the clinician to manage this disease better in the long term, because the severe stages are more difficult to control.

\section{Mechanical treatment}

The backbone of periodontal treatment consists of mechanical removal of bacterial deposits and calculus from the subgingival environment either by hand instruments, or ultrasonic devices, performed either surgically or nonsurgically, along with a strict regimen of plaque control. Although it is known that complete removal of subgingival plaque and calculus is unrealistic, especially as pocket depth increases, ${ }^{11}$ we can expect that the majority of patients with chronic periodontitis will be successfully maintained following both surgical or nonsurgical periodontal therapy. ${ }^{3-6,12-14}$

The main clinical parameter to indicate successful treatment should be tooth loss/maintenance over the years. However, due to numerous difficulties in assessing these parameters, the majority of studies evaluating periodontal 
treatment response look at shorter outcome variables that are easily detected by clinicians, such as PD reduction, CAL gain, and BOP reductions. $\mathrm{Cobb}^{15}$ reports a collection of data from various clinical studies regarding clinical parameters after treatment. He reported that the mean PD reduction for pockets initially measuring 4-6 mm would be $1.29 \mathrm{~mm}$, with a net gain in CAL of $0.55 \mathrm{~mm}$. As periodontal pocket increases ( $\geq 7 \mathrm{~mm}$ ), the mean reduction in PD also increases to $2.16 \mathrm{~mm}$ and CAL to $1.19 \mathrm{~mm}$. The greatest change in these parameters can be seen 1-3 months after therapy. However, other studies have shown additional improvements up to 12 months, with a good maintenance protocol. ${ }^{16-21} \mathrm{BOP}$ is also a very important clinical measurement to assess treatment response because its absence can be used as a criterion for periodontal stability. ${ }^{22}$ Reductions in bleeding may vary with time, from 6\%-64\% at one month, $10 \%-80 \%$ at three months, and $12 \%-87 \%$ at six months..$^{15}$ Thus, evaluations of these parameters should be performed no earlier than four weeks post-therapy, and should be repeated on a continuous basis during maintenance to assess periodontal treatment response.

Different modalities of mechanical therapy have been studied. Numerous studies have reported on the comparative efficiency of sonic and/or ultrasonic versus manual instrumentation, ie, scaling and root planing (SRP). In summary, these studies show that sonic or ultrasonic instrumentation usually provides similar results when compared with manual instrumentation, and generally takes 20\%-50\% less time. ${ }^{17,23,24}$ A combination of the two instruments may be necessary depending on access for different instrumentation, periodontal defect, amount and tenacity of deposits, and patient comfort.

In an attempt to reduce time of treatment and bacterial recolonization, a full-mouth debridement (PSR) or disinfection protocol has been introduced in the literature and extensively evaluated. This protocol consists of mechanical instrumentation within a 24-hour period with or without the use of antiseptics (chlorhexidine). Studies show thus far that both a full-mouth approach and a conventional quadrant SRP approach produce significant results. ${ }^{25}$ Thus, the choice for a full-mouth disinfection approach versus conventional quadrant scaling has to be determined on an individual basis, considering the patient's schedule availability, comfort, and most importantly, severity of disease.

Both surgical and nonsurgical therapies produce significant clinical results. However, more severe disease (deeper pockets) tends to benefit better from surgical therapy. ${ }^{5,26}$ Incidence of disease progression is also greater in sites with deeper PD. These sites tend to respond more favorably when surgical therapy is provided., 5,6,27 Thus, it is important to alert patients with severe chronic periodontitis about the possibility of a second phase of surgical treatment, which could include open flap debridement and bone grafting.

About 20\%-30\% of all chronic periodontitis cases do not respond favorably to conventional periodontal treatment. ${ }^{28,29}$ Many factors may contribute to that response, such as improper removal of bacterial deposits and calculus, poor plaque control, systemic conditions leading to an impaired immune response, defective restorations, occlusal dysfunction, periodontal-endodontic involvement, smoking, and others. In these cases, other treatment approaches may be required to manage refractory or recurrent cases successfully. The challenge with managing such cases is that we cannot always identify other contributing factors or, when identified, these contributing factors may not be modifiable or properly controlled.

\section{Consideration of associated systemic factors in chronic periodontitis}

Periodontal destruction is a result of the host inflammatory reaction to bacterial deposits. The recent literature has highlighted the fact that epithelial lining ulceration due to chronic periodontitis can not only contribute to systemic bacterial dissemination, but also to widespread inflammatory markers in the body. These two pathways have led to numerous studies which have attempted to determine the connection between oral and systemic inflammation and inflammatory diseases, such as diabetes and cardiovascular disease (CVD).

\section{Diabetes mellitus}

Diabetes is a widely studied condition associated with periodontal disease, and affects over 171 million people worldwide. Type 2 diabetes is the most prevalent type, which accounts for $85 \%-95 \%$ of the diabetic population. ${ }^{30}$ Numerous studies have shown a correlation between chronic periodontitis and diabetes, in which both diseases influence the progression and treatment response of the other. ${ }^{31-42}$

A meta-analysis including 3500 diabetic adults concluded that the majority of studies demonstrate more severe chronic periodontitis in diabetic patients than in adults without diabetes. ${ }^{43}$ This confirms a significant association between chronic periodontitis and diabetes. Further studies have shown that, compared with nondiabetic individuals, type 2 diabetics were 2.8 times more likely to have CAL and 3.4 times more likely to have radiographic bone loss than normoglycemic controls. ${ }^{44}$ Moreover, a two-year longitudinal study demonstrated 
that diabetic subjects had an increased risk for alveolar bone loss compared with nondiabetic individuals, with an odds ratio (OR) of 4.2. Among these patients, poorly controlled diabetics had an OR of 11.4 for bone loss compared with an OR of 2.2 for well controlled diabetics. ${ }^{45}$

Chronic periodontitis can also play a role as a metabolic stressor for diabetes control. It can serve as a metabolic stressor that increases insulin resistance or be a continuous source of inflammatory marker secretion, which may amplify the magnitude of advanced glycation end product (AGE)mediated cytokine response and vice versa. ${ }^{46}$ The evidence for the relationship between diabetes and chronic periodontitis have led some to suggest that periodontitis should be listed among the "classic" complications of diabetes. ${ }^{47}$

Some studies have evaluated possible biological mechanisms which explain the relationship between diabetes and periodontal disease. One of these mechanisms is the monocytic hyperresponsiveness to bacterial antigens seen in diabetic populations. This hyperresponse promotes an increased production of proinflammatory cytokines and mediators that result in tissue destruction, attachment loss, and bone loss. ${ }^{48-50}$ Alterations in connective tissue metabolism are also seen in diabetic patients, such as increased collagenase activity in the gingival crevicular fluid of diabetic patients. ${ }^{51}$ Finally, in a hyperglycemic environment, numerous proteins undergo a nonenzymatic glycosylation process, resulting in the formation of AGE. ${ }^{52}$ AGEs binding to macrophages and monocyte receptors induce a hyperresponsive cellular state resulting in increased secretion of the proinflammatory cytokines, interleukin (IL)-1, insulin-like growth factor, and tumor necrosis factor- $\alpha(\mathrm{TNF}-\alpha) \cdot{ }^{53,54}$ These alterations lead to impaired host response, increased tissue destruction, and delayed healing of tissues.

Some studies have attempted to evaluate the effects of periodontal treatment on glycemic control. However, conflicting data exist in the literature regarding this topic. Some studies show that SRP has no influence on metabolic variables, ${ }^{55-57}$ while others report an improvement. ${ }^{58-60}$ Furthermore, reports show that use of systemic antibiotics as an adjunct to SRP may be more beneficial for diabetic patients. Two studies reported that use of systemic doxycycline $100 \mathrm{mg}$ for two weeks provided better reductions in $\mathrm{PD},{ }^{61,62}$ Porphyromonas gingivalis, and glycated hemoglobin $\left(\mathrm{HbA}_{1 \mathrm{c}}\right)$ levels. ${ }^{61}$ when compared with diabetics receiving mechanical therapy alone. However, Rodrigues et al reported that use of amoxicillin-clavulanic acid $875 \mathrm{mg}$ for two weeks did not improve $\mathrm{HbA}_{1 \mathrm{c}}$ levels at three months when compared with SRP alone. ${ }^{63}$ Although it is evident that diabetics will respond to conventional periodontal treatment with or without antibiotics, it is not yet clear if periodontal treatment will have a positive effect on metabolic control.

Thus, it is important to be aware of the patient's complete medical history and to expect that a patient may be less likely to respond favorably to periodontal treatment, depending on their systemic status and control of disease. In this case, a different treatment approach and/or more strict recall intervals for supportive therapy may be necessary.

\section{Cardiovascular disease}

Recently, inflammation has been extensively studied as a contributing factor for CVD. High levels of C-reactive protein (CRP), a marker for systemic inflammation, can predict future acute myocardial infarction, unstable angina pectoris, ${ }^{64,65}$ and the onset of systemic arterial hypertension, diabetes mellitus, and stroke. ${ }^{66-68}$ Other inflammatory markers, such as cytokines, including IL-6, IL-8, IL-10, IL-18, TNF- $\alpha$, and monocyte chemoattractant protein-1 are frequently abnormal in patients with acute coronary syndromes. ${ }^{69,70}$

A meta-analysis linking CVD and chronic periodontitis concluded that chronic periodontitis is a risk factor or marker, which is independent of traditional CVD risk factors, with relative risk estimates ranging from 1.24 to $1.35 .^{71}$ Two possible mechanisms behind that association have been suggested, ie, chronic periodontitis increases inflammatory mediators levels that may contribute to CVD, and treatment of periodontitis reduces systemic levels of these mediators, ${ }^{72-74}$ and certain bacteria species found in periodontal pockets have also been found in atheromatous plaques. ${ }^{75}$

Large, multicenter, clinical studies will be needed to verify this association and to determine the effect periodontal treatment would possibly have on CVD and CVD-associated events.

Based on present knowledge, it does not appear that the treatment protocol for periodontal patients with a history of CVD needs to be modified, because conventional periodontal therapy is effective in these patients. ${ }^{76}$ However, clinicians should be aware of possible associations between periodontal inflammation and the patient's overall health to be able to advise them properly on the potential risks of lack of treatment and the importance of supportive therapy.

\section{Relationship between psychosocial factors and chronic periodontitis}

Stress, anxiety, and depression have been documented as possible contributing factors to periodontal disease. Studies have shown a positive relationship between stress/psychological 
factors and periodontal disease ${ }^{77}$ For instance, individuals with high stress levels tend to adopt habits that are harmful to periodontal health, such as negligent oral hygiene, intensification of nicotine consumption, or changes in eating habits with negative effects on the immune system. ${ }^{78}$ Studies have also elucidated certain biological mechanisms that explain how stress may compromise the host-immune response. These mechanisms could impact disease progression and treatment response. ${ }^{77}$

Among the psychosocial factors, stress, anxiety and depression, the latter has the most significant impact on pain perception, the use of pain medication, and wound healing. ${ }^{79}$ It has been reported that subjects with generalized aggressive periodontitis have significantly higher self-reported depression and loneliness than subjects with routine chronic periodontitis and healthy controls. ${ }^{80}$ Similarly, CAL was associated with increased strain related to job, finances, familial role, depression, and emotion-focused coping. ${ }^{81}$ Oral health care neglect during periods of stress and depression has been associated with CAL and missing teeth. ${ }^{82}$ Thus, aggressive periodontitis, attachment loss, and poor immune responses ${ }^{82}$ appear to be directly influenced by, or potentially linked to, certain psychosocial factors.

\section{Influence of psychosocial factors on treatment outcome}

Accounting for the patient's psychosocial condition is essential for the patients' successful treatment response. In a retrospective cohort study, patients with depression had a negative periodontal treatment outcome over one year compared with patients without depression. ${ }^{83}$ This could be explained by the fact that depressed patients also display delayed wound healing compared with nondepressed patients. ${ }^{84}$ Positive coping mechanisms and enhanced perceptions of positive outcomes have been demonstrated to have a positive effect on wound healing. ${ }^{85}$

Despite findings that depression has a negative impact in wound healing and promotes the acquisition of harmful behaviors, it is probably the least appreciated relevant psychological factor by practicing periodontists. ${ }^{79}$ Studies have shown that more providers indicated that they gave different instructions to anxious patients $(55.6 \%)$ than to stressed patients $(41.5 \%)$ or depressed patients $(26.3 \%) .{ }^{79}$ This could be explained by the fact that the provider's confidence in their ability to identify depressed patients is lower than their ability to identify anxious or stressed patients (means $3.45,4.31$, and 4.29 , respectively). ${ }^{79}$
Dentists should be aware of the negative impact psychosocial factors may have on periodontal health, as well as the patient's treatment outcome, in order to delineate proper treatment plans. In depressed patients, the treatment response may not be as favorable as normally expected. Healing could be delayed, and depending on severity of the case, the treatment plan may require re-evaluation.

\section{Smoking and periodontal disease}

According to the Centers for Disease Control and Prevention, $20.8 \%$ of the US population smoked in 2008, with slightly higher rates in males than females $(23.5 \%$ versus $18.3 \%$ ). Smoking is considered the most important risk factor for chronic periodontitis. Smoking plays a crucial role in its prevalence, incidence, severity, progression, and the treatment response. ${ }^{86-91}$ In fact, smoking is such a strong factor for chronic periodontitis that even passive smokers are at higher risk for developing chronic periodontitis. ${ }^{92,93}$ Smokers have six to seven times more alveolar bone loss than nonsmokers. ${ }^{87,91,94,95}$ Patients with chronic periodontitis are also three to five times more likely to smoke than those without attachment loss. ${ }^{95}$

Periodontal treatment in smokers is challenging. Smokers will respond less favorably to both nonsurgical and surgical periodontal treatment than nonsmokers. ${ }^{86,88,89,96}$ Reports show that heavy or light smokers have less pocket depth reduction and less attachment gain, relative to nonsmokers and past-smokers, following active treatment and throughout supportive periodontal phase. A study that followed patients over seven years of maintenance therapy reported that smokers experienced greater attachment loss relative to nonsmokers. ${ }^{88}$ Because smoking has such a deleterious effect on periodontal treatment response, some studies have aimed to seek alternative treatment approaches for these patients. These studies have found smokers respond less favorably to periodontal therapy than nonsmokers, regardless of therapy received. However, use of systemic ${ }^{97,98}$ and local ${ }^{99-101}$ antibiotics as adjuncts to SRP may provide an additional benefit in the treatment response of smokers.

Among current US adult smokers, 70\% report a desire to quit completely, and millions have attempted to quit smoking. ${ }^{102}$ In 2007, an estimated 47 million adults (aged 18 years and older) were former smokers and $40 \%$ of adult smokers (13 million people) stopped smoking for at least one day in the year of 2008 while trying to quit. Interestingly, past-smokers respond similarly to periodontal therapy and maintenance relative to never-smokers. ${ }^{86-88,95}$ In addition, 
implant survival rates are higher in past-smokers than current smokers. ${ }^{103}$

As a professional health provider, it has become increasingly important for the dentist to provide patients with proper counseling on the relationship between smoking and chronic periodontitis, and to encourage smoking cessation whenever the patient reports a willingness to quit. Unfortunately only $24 \%$ of dentists recommend their patients to stop smoking. ${ }^{104}$ See http://www.cdc.gov/tobacco for some guidelines about effective methods of smoking cessation.

\section{Controlling local contributing factors}

Severity of disease, furcation involvement, patient plaque control, plaque retentive factors (defective restorations, caries), and occlusal trauma are among the local factors that can limit successful periodontal treatment.

Deeper pockets and intrabony defects represent difficult areas for subgingival instrumentation. The deeper the pocket, the fewer subgingival deposits are removed. ${ }^{11}$ Also, molar teeth with furcation involvement tend to present a poorer response to periodontal treatment than those without. ${ }^{105,106}$ Difficult access and operator skills could contribute to incomplete removal of subgingival bacterial deposits and impair the healing response. ${ }^{11,107-110}$ Surgical intervention may improve the removal of subgingival deposits in areas of difficult access. ${ }^{109,110}$ Therefore, dentists need to diagnose areas of difficult access carefully so that patients are aware of possible future surgical intervention.

Plaque control is essential for good periodontal treatment response. Patients who receive plaque control instructions and reinforcement have a better response and stability of clinical results, as well as low levels of subgingival bacteria relative to patients not placed on a plaque control regimen. ${ }^{111}$ In the absence of plaque control, microbial repopulation of treated areas as well as a return to pretreatment pocket depths will occur within a few weeks after periodontal instrumentation. ${ }^{111-113}$

Improper restorations can result in two major problems for periodontal healing, ie, plaque accumulation and biological width invasion. Defective margins act as a niche for biofilm accumulation, which impairs proper healing response. In addition, crown or restoration margins, when placed in proximal tooth surfaces, may impinge on the periodontal biological width. Biological width consists of a space of about $2 \mathrm{~mm}$ from the cemento-enamel junction to the bone crest that includes the junctional epithelium and connective tissue attachment. ${ }^{114,115}$ However, one must realize that significant variations in biological width dimensions have been observed, particularly the epithelial attachment, which may vary from 1.0 to $9.0 \mathrm{~mm} .{ }^{114}$ Placing a restorative material in the biological space will most likely result in an inflammatory process and future attachment and bone loss to the area. ${ }^{116-118}$ Gunay et al noted greater bleeding index and PD when restorations were placed $<1 \mathrm{~mm}$ from the bone crest. ${ }^{119}$ Dentists need to be aware of biological width invasion when treatment planing a patient for periodontal treatment. Areas of biological width that have been violated will most likely not respond to periodontal treatment due to persistent plaque accumulation and inflammation.

\section{Trauma from occlusion}

Trauma from occlusion is defined as an "injury to the periodontium resulting from occlusal forces which exceeds the reparative capacity of the attachment apparatus", ie, the tissue injury occurs because the periodontium is unable to cope with the increased stresses it experiences. ${ }^{120}$ Occlusal trauma can occur in conjunction with or independent of inflammatory diseases. The ability of the attachment apparatus to withstand a less than ideal occlusion may be compromised by periodontal inflammation. Thus, trauma from occlusion may accelerate attachment loss in a patient with active chronic periodontitis. $^{120}$

Clinical diagnosis of occlusal trauma should be part of the chronic periodontitis treatment plan. The signs of occlusal trauma include: tooth mobility (increasing displacement may be of greater concern since a stable pattern of mobility may indicate adaptation); tooth migration; tooth pain or discomfort on chewing or percussion; radiographic changes; tenderness of mastication muscles or other signs or symptoms of temporomandibular dysfunction; presence of wear facets beyond expected levels for the patient's age and diet consistency; chipped enamel or crown/root fractures; and fremitus. ${ }^{121}$

Radiographic changes include widening of the periodontal ligament space, disruption of the lamina dura, radiolucencies in the furcation or at the apex of a tooth that is vital, or root resorption. As with mobility, stable radiographic findings may indicate adaptation. It is important to note that when found in conjunction with chronic periodontitis, occlusal trauma can usually be diagnosed in areas of vertical or U-shaped bone defects (Figure 1). As seen in Figure 2, trauma does not always come from occlusion interferences.

If trauma from occlusion is detected concomitantly with a diagnosis of chronic periodontitis, the treatment plan should include occlusal adjustment to reduce the trauma. 


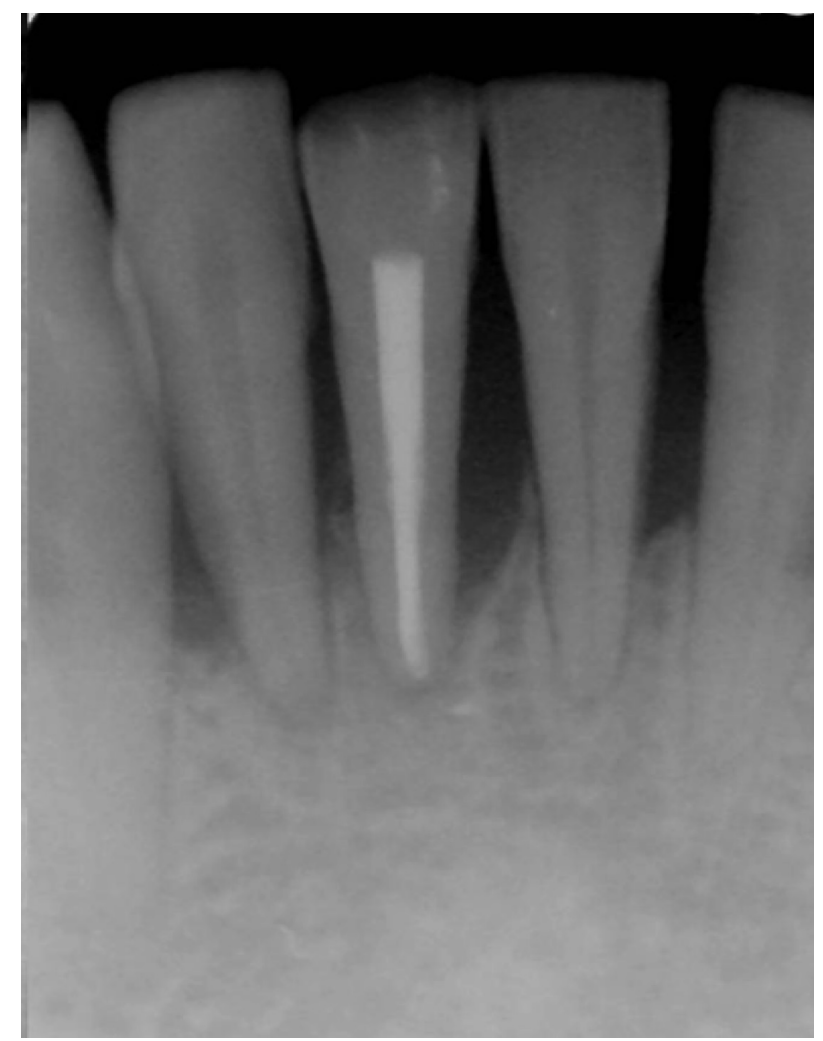

Figure I Radiographic sign of chronic periodontitis and occlusal trauma. Note wear facet on lower right incisor.

Teeth with greater mobility present less favorable changes after periodontal treatment than firmer teeth. ${ }^{122}$ Occlusal adjustment has also been shown to reduce tooth mobility. ${ }^{123}$ Furthermore, periodontal treatment in conjunction with occlusal adjustment tends to result in a slightly more favorable attachment level gain than treatment without occlusal adjustment. ${ }^{124}$ Therefore, occlusal therapy needs to be

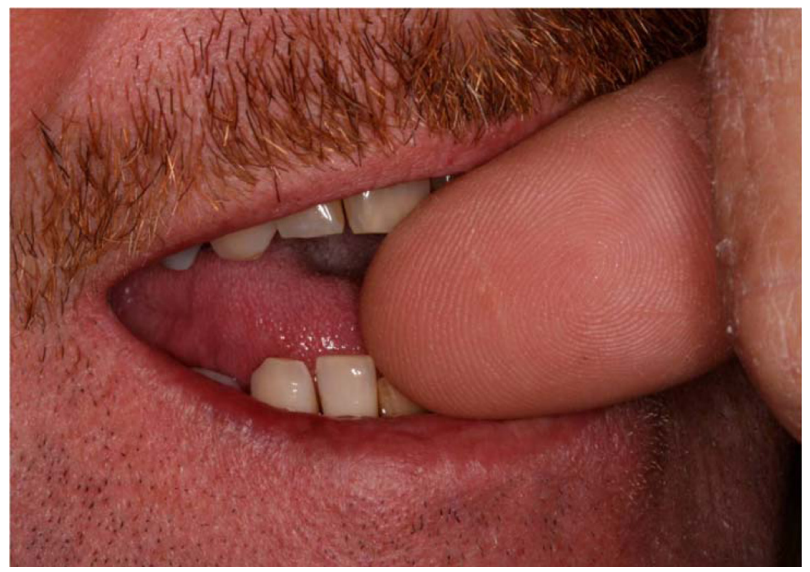

Figure 2 Cause of trauma on that area in the patient was actually a harmful habit of nail-biting. Note position of thumb nail on distal incisal edge of central incisor and pressure applied on mesial edge of lateral incisor. addressed when possible, following or in conjunction with, procedures to resolve inflammatory lesions.

Given the possible negative effects of trauma from occlusion in the periodontium, periodontal treatment planing should include a thorough analysis of occlusion to detect possible occlusal interferences and trauma. Furthermore, occlusal adjustment should be performed as part of periodontal treatment, when indicated, in order to maximize treatment outcomes.

\section{Use of antibiotics}

Although a considerable body of evidence indicates that adjunctive use of antibiotics provide some additional benefit in chronic periodontitis treatment, ${ }^{125}$ a number of reasons exist to preclude their indiscriminate use. As discussed earlier, most chronic periodontitis patients respond well to mechanical therapy, and adjunctive antimicrobial therapy adds little, if any, benefit for these patients. Additionally, the concern about antibiotic resistance exists. This is not a new problem and has been recognized for years. Walker documented a two-fold increase, over a 10-year period, in the proportion of the cultivable subgingival flora in patients resistant to penicillins and tetracyclines. ${ }^{126}$ It is very likely that the proportion of subgingival flora resistant to systemic achievable antibiotic levels is even higher today. Current thinking is that if there is not a clear need to use an antibiotic, then it should not be used.

However, this does not help the clinician who is faced with a patient who does not respond favorably to mechanical therapy. As previously discussed, $20 \%-30 \%$ of chronic periodontitis patients may not respond to mechanical therapy alone. This may be due to a variety of factors, as discussed previously. For such patients, an adjunctive antibiotic combined with SRP is often advantageous. The question arises of which antibiotic to use. New techniques, such as 16S RNA sequencing, have revealed that the human oral cavity contains over 700 different bacterial species, many of which are presently uncultivable. ${ }^{127}$ Within a given individual, there may be as many as 100 different species. This is further complicated by the fact that subgingival plaque exists as a biofilm. These biofilms are significantly more resistant, up to and greater than 500 times, to antibiotics than are the same bacteria grown planktonically. ${ }^{128}$ This means that our current concepts regarding antibiotic susceptibilities and resistances based on in vitro testing of pure cultures in broth or agar media are not applicable to biofilms. Bacteria in the biofilm demonstrate a much slower metabolism than planktonic-grown bacteria due to the limited nutrients available. An antibiotic must penetrate 
the bacterial cell to exert its antimicrobial effect. This is more difficult in a biofilm, due to the biofilm's thickness and its protective extrapolysaccaharide matrix. Additionally, in order to be effective, antibiotics generally require that bacteria actively metabolize nutrients, synthesize proteins and cell wall components, or replicate their DNA. The slower metabolic rate and barriers associated with penetration of antibiotics into mature biofilms decrease the effectiveness associated with antibiotics.

Another factor that works against antibiotics is that certain periodontal pathogens have the ability to penetrate into host cells. Examples of this are Porphyromonas gingivalis, Acinobacillus actinomycetemcomitans, and Fusobacterium nucleatum, among others. The systemic delivery of many antibiotics does not achieve a sufficient concentration within mammalian cells to be inhibitory or to kill bacteria. Once subgingival plaque in periodontal pockets is mechanically removed, these invasive bacteria are capable of recolonizing the pocket and may exacerbate the disease process.

The question most frequently asked by the clinician is what antibiotic to use when the patient experiences recurrent disease or when individual sites do not respond satisfactorily. Unfortunately, a single antibiotic that can be recommended for all patients does not exist. Susceptibility testing of subgingival flora can be beneficial and provide some guidance to the clinician (see Shaddox and Walker for review $\left.^{129}\right)$. However, very few laboratories offer this service. Furthermore, accuracy of susceptibility testing is directly dependent on the collection of a representative sample and protection of this sample from oxidation, both during collection and shipment to the laboratory, given that most periodontal pathogens are strictly anaerobes. At present, DNA probes for the determination of antibiotic-resistant markers are not available. The susceptibility results are based solely on the ability to cultivate the bacteria that were collected from the site(s) in question. The proportion of the flora that is uncultivated will not be recovered or assessed for its susceptibility to an antibiotic. Thus, the clinician is often required to make a decision on what antibiotic to use among many choices. No large clinical trials have been conducted to ascertain the relative effectiveness of various antibiotics in the adjunctive treatment of chronic periodontitis. At present, the drug of choice, based on empiric usage, as well as small-scale clinical testing, is the combination of amoxicillin (250-500 mg) and metronidazole (250-500 mg) given three times daily for seven to 10 days. ${ }^{130-133}$ The best results are generally obtained when this combination is given as an adjunct to SRP. If the patient is allergic to penicillins, then alternatives, such as doxycycline, minocycline, or metronidazole may be beneficial. ${ }^{134,135}$ The combination of metronidazole and ciprofloxacin has been recommended where either enteric bacteria, pseudomonads, and/or $A$. actinomycetemcomitans are suspected. ${ }^{136}$ It is important to note that for the treatment of aggressive periodontitis, adjunctive use of antimicrobials is recommended, given the consistent additional benefits it provides when compared with SRP alone. ${ }^{125,134}$

The above antibiotics are delivered systemically. Local delivery antibiotics that are placed directly into the individual periodontal pocket that requires additional treatment have an attractive appeal. Several antibiotics have been incorporated into a continuous-release system that delivers high drug concentrations directly in the periodontal pocket. These have included hollow fibers containing tetracycline, ${ }^{137,138}$ and biodegradable-release systems that contain either metronidazole, doxycycline, or minocycline. ${ }^{139}$ Of these four, only controlled-release doxycycline and minocycline are currently available in this country. Both of these local delivery systems have demonstrated improvements in clinical parameters and a decrease in biofilm mass relative to placebo controls. Doxycycline, in particular, has been demonstrated to have an effect on several putative periodontal pathogens as well as the total bacterial mass. ${ }^{135,140,141}$ A controlled-release, local-delivery antibiotic is very desirable for treating individual periodontal sites for several obvious reasons. Firstly, the drug is delivered locally and does not promote resistance in other regions of the body. Secondly, it remains in place for 10-14 days. Thirdly, it delivers a much higher drug concentration than can be achieved systemically. However, local delivery has not been widely accepted by the profession. Reasons for this include the learning curve associated with the use of these systems, the time involved in placement of the drug in the desired sites, the cost of the system, and the clinical significance of the additional results obtained. However, both locally delivered doxycycline and minocycline have shown positive additional benefits in the treatment of smokers when compared with SRP ${ }^{99-101,140-142}$ and in the treatment of nonresponding pockets. ${ }^{99,143}$ These drugs are packaged in syringes. Doxycycline syringes contain sufficient drug to treat a number of sites, whereas each minocycline syringe is applied in one pocket. Therefore, due to cost of these drugs and effectiveness of mechanical treatment alone in the majority of sites, local antibiotics could be applicable in a limited number of sites that do not respond to initial treatment. 


\section{Low-dose tetracyclines}

Tetracyclines are also known to confer host-modulatory effects, ie, inhibition of collagenase activity in the gingival tissues of patients with chronic periodontitis. ${ }^{144}$ Thus, a low nonantimicrobial dose of doxycycline $40 \mathrm{mg}$ daily, has been used as an adjunctive treatment of chronic periodontitis. Studies have shown additional clinical benefits with the use of subantimicrobial dose doxycycline in conjunction with SRP when compared with SRP and placebo. ${ }^{145}$ These benefits over SRP alone are especially prominent in deeper sites and in smokers.

In conclusion, for the chronic periodontitis patient who does not uniformly respond favorably to mechanical treatment, the adjunctive use of an antibiotic may be beneficial. Unfortunately, no single antibiotic is considered a "magic bullet" for use in adjunctive treatment of chronic periodontitis. Therefore, clinicians have to make a decision about which drug or delivery system to use on an individual basis, taking into consideration the number of nonresponding sites, contributing factors associated with nonresponse, patient allergies, and disease type.

\section{Laser therapy for chronic periodontitis}

Although the first laser prototype was developed in 1960 , the use of lasers in dentistry is fairly recent. Lasers have increasingly been studied in the literature and have become a very attractive tool in general dentistry, especially for soft tissue procedures. Despite the large number of published studies, controversy continues among clinicians regarding the use of lasers for chronic periodontitis treatment. Studies do support the fact that lasers, such as Nd:YAG and Er:YAG, achieve a reduction in the number of periodontal pathogens and pocket depth. However, the evidence is currently insufficient to support greater benefits of lasers over traditional SRP or additional benefits when used in conjunction with SRP in the treatment of chronic periodontitis (see Cobb for review $\left.{ }^{146}\right)$.

\section{Supportive periodontal care}

The third and final challenge of chronic periodontitis management is establishing successful periodontal treatment planing to maintain periodontal stability and minimize further attachment loss. The challenge in this phase is maintaining patient compliance and identifying as well as managing factors associated with the disease.

Patient compliance with plaque control and follow-up visits is essential for successful management of periodontitis.
The rate of tooth loss is two times higher for patients treated and nonmaintained compared with treated and well maintained. ${ }^{147}$ The more often patients are present for maintenance visits, the less likely they are to lose teeth. ${ }^{148}$ Furthermore, patients who are placed on a strict recall maintenance program have less bleeding on probing scores and attachment loss over long-term follow-up. For instance, Axelson and Lindhe ${ }^{149}$ have found probing attachment loss $\geq 2 \mathrm{~mm}$ for $1 \%$ of all examined sites in a strict recall group (patients placed on a $2-3$ month maintenance program) versus $56 \%$ of sites in a nonrecall group.

Patients with chronic illnesses tend to comply poorly, especially if the disease is not perceived to be threatening. ${ }^{148}$ Studies have also shown that patient compliance with visits is around 30\%-40\%. ${ }^{107,150,151}$ Most noncompliant visits happen within the first year of maintenance, which indicates that patients are more likely to remain compliant if they continue supportive treatment for at least the first year. ${ }^{150}$ The reasons for noncompliance are highly variable, and may include fear, economics, and lack of compassion from the dental therapist. ${ }^{148}$

A few randomized, controlled, clinical studies have evaluated the individual benefit or required frequency of periodontal maintenance ritual for patients who are relatively susceptible to chronic periodontitis. Due to individual variations in susceptibility to periodontal disease progression, and different factors associated with periodontal treatment response, professional maintenance care must be determined on an individual basis. Thus, the more factors associated with disease progression and a negative treatment response the individual presents, the shorter the supportive care recalls should be.

\section{Summary and conclusions}

Good plaque control, as well as removal of bacteria, calculus deposits, and granulation tissue by mechanical instrumentation constitutes an effective approach to reduce signs of inflammation in most cases of chronic periodontitis. However, knowing that this disease is multifaceted, dentists need to be aware of other factors, local and systemic, that could contribute to the disease process and healing response. Therefore, diagnosing chronic periodontitis at an early stage and evaluating each possible contributing factor is essential for successful long-term management of periodontal stability.

\section{Future directions}

Greater awareness of periodontal disease and diagnostic methods will hopefully motivate dentists to diagnose 
periodontitis and its contributing factors better at earlier stages. This will hopefully enable improved disease management and prevention of disease progression. Future studies will be able to clarify further the role of factors contributing to periodontitis and how management of these factors can influence the control of disease and vice versa. More randomized controlled clinical trials will be able to answer which treatment approach will best manage periodontitis associated with different contributing factors. More studies will be able to elucidate individual susceptibility to disease and future breakdown and thus, enable clinicians to better plan for successful periodontal treatment and supportive care.

\section{Disclosure}

The authors report no conflict of interest in this research.

\section{References}

1. Burt B. Position paper: Epidemiology of periodontal diseases. J Periodontol. 2005;76:1406-1409.

2. Page RC, Eke PI. Case definitions for use in population-based surveillance of periodontitis. J Periodontol. 2007;78:1387-1399.

3. Hill RW, Ramfjord SP, Morrison EC, et al. Four types of periodontal treatment compared over two years. J Periodontol. 1981;52:655-662.

4. Isidor F, Karring T. Long-term effect of surgical and non-surgical periodontal treatment. A 5-year clinical study. J Periodontal Res. 1986;21:462-472.

5. Kaldahl WB, Kalkwarf KL, Patil KD, Molvar MP, Dyer JK. Longterm evaluation of periodontal therapy: I. Response to 4 therapeutic modalities. J Periodontol. 1996;67:93-102.

6. Kaldahl WB, Kalkwarf KL, Patil KD, Molvar MP, Dyer JK. Longterm evaluation of periodontal therapy: II. Incidence of sites breaking down. J Periodontol. 1996;67:103-108.

7. Brunsvold MA, Nair P, Oates TW Jr. Chief complaints of patients seeking treatment for periodontitis. J Am Dent Assoc. 1999;130:359-364.

8. Khocht A, Zohn H, Deasy M, Chang KM. Assessment of periodontal status with PSR and traditional clinical periodontal examination. J Am Dent Assoc. 1995;126:1658-1665.

9. Greenstein G. Contemporary interpretation of probing depth assessments: Diagnostic and therapeutic implications. A literature review. J Periodontol. 1997;68:1194-1205.

10. Jeffcoat MK, Reddy MS. A comparison of probing and radiographic methods for detection of periodontal disease progression. Curr Opin Dent. 1991;1:45-51.

11. Stambaugh RV, Dragoo M, Smith DM, Carasali L. The limits of subgingival scaling. Int J Periodontics Restorative Dent. 1981;1:30-41.

12. Lindhe J, Nyman S. Long-term maintenance of patients treated for advanced periodontal disease. J Clin Periodontol. 1984; 11:504-514.

13. Lindhe J, Westfelt E, Nyman S, Socransky SS, Haffajee AD. Long-term effect of surgical/non-surgical treatment of periodontal disease. J Clin Periodontol. 1984;11:448-458.

14. Ramfjord SP, Caffesse RG, Morrison EC, et al. Four modalities of periodontal treatment compared over five years. J Periodontal Res. 1987;22:222-223.

15. Cobb CM. Non-surgical pocket therapy: Mechanical. Ann Periodontol. 1996;1:443-490.

16. Badersten A, Nilveus R, Egelberg J. Effect of nonsurgical periodontal therapy. III. Single versus repeated instrumentation. J Clin Periodontol. 1984;11:114-124.
17. Badersten A, Nilveus R, Egelberg J. Effect of nonsurgical periodontal therapy. II. Severely advanced periodontitis. J Clin Periodontol. 1984; 11:63-76.

18. Cugini MA, Haffajee AD, Smith C, Kent RL Jr. Socransky SS. The effect of scaling and root planing on the clinical and microbiological parameters of periodontal diseases: 12 -month results. J Clin Periodontol. 2000;27:30-36.

19. Kaldahl WB, Kalkwarf KL, Patil KD, Dyer JK, Bates RE Jr. Evaluation of four modalities of periodontal therapy. Mean probing depth, probing attachment level and recession changes. J Periodontol. 1988;59:783-793.

20. Morrison EC, Ramfjord SP, Hill RW. Short-term effects of initial, nonsurgical periodontal treatment (hygienic phase). J Clin Periodontol. 1980;7:199-211.

21. Preshaw PM, Lauffart B, Zak E, et al. Progression and treatment of chronic adult periodontitis. J Periodontol. 1999;70:1209-1220.

22. Lang NP, Joss A, Orsanic T, Gusberti FA, Siegrist BE. Bleeding on probing. A predictor for the progression of periodontal disease? J Clin Periodontol. 1986;13:590-596.

23. Checchi L, Pelliccioni GA. Hand versus ultrasonic instrumentation in the removal of endotoxins from root surfaces in vitro. $J$ Periodontol. 1988;59:398-402.

24. Dragoo MR. A clinical evaluation of hand and ultrasonic instruments on subgingival debridement. 1. With unmodified and modified ultrasonic inserts. Int J Periodontics Restorative Dent. 1992;12:310-323.

25. Eberhard J, Jepsen S, Jervoe-Storm PM, Needleman I, Worthington HV. Full-mouth disinfection for the treatment of adult chronic periodontitis. Cochrane Database Syst Rev. 2008:CD004622.

26. Serino G, Rosling B, Ramberg P, Socransky SS, Lindhe J. Initial outcome and long-term effect of surgical and non-surgical treatment of advanced periodontal disease. J Clin Periodontol. 2001;28:910-916.

27. Heitz-Mayfield LJ, Trombelli L, Heitz F, Needleman I, Moles D. A systematic review of the effect of surgical debridement vs non-surgical debridement for the treatment of chronic periodontitis. J Clin Periodontol. 2002;29 Suppl 3:92-102; discussion 160-162.

28. Hirschfeld L, Wasserman B. A long-term survey of tooth loss in 600 treated periodontal patients. J Periodontol. 1978;49:225-237.

29. McFall WT Jr. Tooth loss in 100 treated patients with periodontal disease. A long-term study. J Periodontol. 1982;53:539-549.

30. Mokdad AH, Bowman BA, Ford ES, et al. The continuing epidemics of obesity and diabetes in the United States. JAMA. 2001;286:1195-1200.

31. Albrecht M, Banoczy J, Tamas G Jr. Dental and oral symptoms of diabetes mellitus. Community Dent Oral Epidemiol. 1988;16:378-380.

32. Bernick SM, Cohen DW, Baker L, Laster L. Dental disease in children with diabetes mellitus. J Periodontol. 1975;46:241-245.

33. Cianciola LJ, Park BH, Bruck E, Mosovich L, Genco RJ. Prevalence of periodontal disease in insulin-dependent diabetes mellitus (juvenile diabetes). J Am Dent Assoc. 1982;104:653-660.

34. Cohen DW, Friedman LA, Shapiro J, Kyle GC, Franklin S. Diabetes mellitus and periodontal disease: Two-year longitudinal observations. I. J Periodontol. 1970;41:709-712.

35. de Pommereau V, Dargent-Pare C, Robert JJ, Brion M. Periodontal status in insulin-dependent diabetic adolescents. J Clin Periodontol. 1992;19:628-632.

36. Ervasti T, Knuuttila M, Pohjamo L, Haukipuro K. Relation between control of diabetes and gingival bleeding. J Periodontol. 1985;56:154-157.

37. Galea H, Aganovic I, Aganovic M. The dental caries and periodontal disease experience of patients with early onset insulin dependent diabetes. Int Dent J. 1986;36:219-224.

38. Gusberti FA, Syed SA, Bacon G, Grossman N, Loesche WJ. Puberty gingivitis in insulin-dependent diabetic children. I. Cross-sectional observations. J Periodontol. 1983;54:714-720.

39. Hugoson A, Thorstensson H, Falk H, Kuylenstierna J. Periodontal conditions in insulin-dependent diabetics. J Clin Periodontol. $1989 ; 16: 215-223$. 
40. Novaes Junior AB, Pereira AL, de Moraes N, Novaes AB. Manifestations of insulin-dependent diabetes mellitus in the periodontium of young Brazilian patients. J Periodontol. 1991;62:116-122.

41. Rylander H, Ramberg P, Blohme G, Lindhe J. Prevalence of periodontal disease in young diabetics. J Clin Periodontol. 1987;14:38-43.

42. Seppala B, Seppala M, Ainamo J. A longitudinal study on insulindependent diabetes mellitus and periodontal disease. J Clin Periodontol. 1993;20:161-165.

43. Papapanou PN. Periodontal diseases: Epidemiology. Ann Periodontol. 1996;1:1-36.

44. Emrich LJ, Shlossman M, Genco RJ. Periodontal disease in non-insulindependent diabetes mellitus. J Periodontol. 1991;62:123-131.

45. Taylor GW, Burt BA, Becker MP, et al. Non-insulin dependent diabetes mellitus and alveolar bone loss progression over 2 years. J Periodontol. 1998;69:76-83.

46. Mealey BL, Oates TW. Diabetes mellitus and periodontal diseases. J Periodontol. 2006;77:1289-1303.

47. Loe H. Periodontal disease. The sixth complication of diabetes mellitus. Diabetes Care. 1993;16:329-334.

48. Naguib G, Al-Mashat H, Desta T, Graves DT. Diabetes prolongs the inflammatory response to a bacterial stimulus through cytokine dysregulation. J Invest Dermatol. 2004;123:87-92.

49. Salvi GE, Collins JG, Yalda B, et al. Monocytic TNF alpha secretion patterns in IDDM patients with periodontal diseases. J Clin Periodontol. 1997;24:8-16.

50. Salvi GE, Yalda B, Collins JG, et al. Inflammatory mediator response as a potential risk marker for periodontal diseases in insulin-dependent diabetes mellitus patients. $J$ Periodontol. 1997;68:127-135.

51. Sorsa T, Ingman T, Suomalainen K, et al. Cellular source and tetracycline-inhibition of gingival crevicular fluid collagenase of patients with labile diabetes mellitus. J Clin Periodontol. 1992;19:146-149.

52. Monnier VM, Glomb M, Elgawish A, Sell DR. The mechanism of collagen cross-linking in diabetes: A puzzle nearing resolution. Diabetes. 1996;45 Suppl 3:S67-S72.

53. Schmidt AM, Hori O, Cao R, et al. RAGE: A novel cellular receptor for advanced glycation end products. Diabetes. 1996;45 Suppl 3: S77-S80.

54. Schmidt AM, Yan SD, Wautier JL, Stern D. Activation of receptor for advanced glycation end products: A mechanism for chronic vascular dysfunction in diabetic vasculopathy and atherosclerosis. Circ Res. 1999;84:489-497.

55. Christgau M, Palitzsch KD, Schmalz G, Kreiner U, Frenzel S. Healing response to non-surgical periodontal therapy in patients with diabetes mellitus: Clinical, microbiological, and immunologic results. J Clin Periodontol. 1998;25:112-124.

56. Seppala B, Ainamo J. A site-by-site follow-up study on the effect of controlled versus poorly controlled insulin-dependent diabetes mellitus. J Clin Periodontol. 1994;21:161-165.

57. Smith GT, Greenbaum CJ, Johnson BD, Persson GR. Short-term responses to periodontal therapy in insulin-dependent diabetic patients. J Periodontol. 1996;67:794-802.

58. Faria-Almeida R, Navarro A, Bascones A. Clinical and metabolic changes after conventional treatment of type 2 diabetic patients with chronic periodontitis. J Periodontol. 2006;77:591-598.

59. Kiran M, Arpak N, Unsal E, Erdogan MF. The effect of improved periodontal health on metabolic control in type 2 diabetes mellitus. J Clin Periodontol. 2005;32:266-272.

60. Stewart JE, Wager KA, Friedlander AH, Zadeh HH. The effect of periodontal treatment on glycemic control in patients with Type 2 diabetes mellitus. J Clin Periodontol. 2001;28:306-310.

61. Grossi SG, Skrepcinski FB, DeCaro T, et al. Treatment of periodontal disease in diabetics reduces glycated hemoglobin. J Periodontol. 1997;68:713-719.

62. Llambes F, Silvestre FJ, Hernandez-Mijares A, Guiha R, Caffesse R. Effect of non-surgical periodontal treatment with or without doxycycline on the periodontium of type 1 diabetic patients. J Clin Periodontol. 2005;32:915-920.
63. Rodrigues DC, Taba MJ, Novaes AB, Souza SL, Grisi MF. Effect of non-surgical periodontal therapy on glycemic control in patients with Type 2 diabetes mellitus. J Periodontol. 2003;74:136-137.

64. Berk BC, Weintraub WS, Alexander RW. Elevation of C-reactive protein in "active" coronary artery disease. Am J Cardiol. 1990;65:168-172.

65. de Beer FC, Hind CR, Fox KM, et al. Measurement of serum Creactive protein concentration in myocardial ischaemia and infarction. Br Heart J. 1982;47:23-43.

66. Ridker PM, Cushman M, Stampfer MJ, Tracy RP, Hennekens CH. Inflammation, aspirin, and the risk of cardiovascular disease in apparently healthy men. $N$ Engl J Med. 1997;336:973-979.

67. Ridker PM, Glynn RJ, Hennekens CH. C-reactive protein adds to the predictive value of total and HDL cholesterol in determining risk of first myocardial infarction. Circulation. 1998;97: 2007-2011.

68. Sesso HD, Buring JE, Rifai N, et al. C-reactive protein and the risk of developing hypertension. JAMA. 2003;290:2945-2951.

69. Armstrong EJ, Morrow DA, Sabatine MS. Inflammatory biomarkers in acute coronary syndromes: Part IV: Matrix metalloproteinases and biomarkers of platelet activation. Circulation. 2006;113:e382-e385.

70. Inoue $\mathrm{T}$, Komoda $\mathrm{H}$, Nonaka $\mathrm{M}$, et al. Interleukin- 8 as an independent predictor of long-term clinical outcome in patients with coronary artery disease. Int J Cardiol. 2008;124:319-325.

71. Humphrey LL, Fu R, Buckley DI, Freeman M, Helfand M. Periodontal disease and coronary heart disease incidence: A systematic review and meta-analysis. J Gen Intern Med. 2008;23:2079-2086.

72. D'Aiuto F, Parkar M, Nibali L, et al. Periodontal infections cause changes in traditional and novel cardiovascular risk factors: Results from a randomized controlled clinical trial. Am Heart J. 2006;151:977-984.

73. Paraskevas S, Huizinga JD, Loos BG. A systematic review and metaanalyses on C-reactive protein in relation to periodontitis. $J$ Clin Periodontol. 2008;35:277-290.

74. Tonetti MS, D'Aiuto F, Nibali L, et al. Treatment of periodontitis and endothelial function. N Engl J Med. 2007;356:911-920.

75. Haraszthy VI, Zambon JJ, Trevisan M, Zeid M, Genco RJ. Identification of periodontal pathogens in atheromatous plaques. J Periodontol. 2000;71:1554-1560.

76. Offenbacher S, Beck JD, Moss K, et al. Results from the Periodontitis and Vascular Events (PAVE) Study: A pilot multicentered, randomized, controlled trial to study effects of periodontal therapy in a secondary prevention model of cardiovascular disease. J Periodontol. 2009;80:190-201

77. Peruzzo D, Benatti B, Ambrosano G, et al. A systematic review of stress and psychological factors as possible risk factors for periodontal disease. J Periodontol 2007;78:1491-1504.

78. Genco RJ, Ho AW, Kopman J, et al. Models to evaluate the role of stress in periodontal disease. Ann Periodontol. 1998;3:288-302.

79. Kloostra P, Eber R, Inglehart M. Anxiety, stress, depression, and patients' responses to periodontal treatment: Periodontists' knowledge and professional behavior. J Periodontol. 2007;78:64-71.

80. Monteiro da Silva AM, Oakley DA, Newman HN, Nohl FS, Lloyd HM. Psychosocial factors and adult onset rapidly progressive periodontitis. J Clin Periodontol. 1996;23:789-794.

81. Ng SK, Keung Leung W. A community study on the relationship between stress, coping, affective dispositions and periodontal attachment loss. Community Dent Oral Epidemiol. 2006;34:252-266.

82. Rosania AE, Low KG, McCormick CM, Rosania DA. Stress, depression, cortisol, and periodontal disease. J Periodontol. 2009; 80:260-266.

83. Elter JR, White BA, Gaynes BN, Bader JD. Relationship of clinical depression to periodontal treatment outcome. J Periodontol. 2002;73:441-449.

84. Cole-King A, Harding KG. Psychological factors and delayed healing in chronic wounds. Psychosom Med. 2001;63:216-220.

85. Feeney S. The relationship between pain and negative affect in older adults: Anxiety as a predictor of pain. J Anxiety Disord. 2004;18:733-744. 
86. Ah MK, Johnson GK, Kaldahl WB, Patil KD, Kalkwarf KL. The effect of smoking on the response to periodontal therapy. J Clin Periodontol. 1994;21:91-97.

87. Grossi SG, Genco RJ, Machtei EE, et al. Assessment of risk for periodontal disease. II. Risk indicators for alveolar bone loss. J Periodontol. 1995;66:23-29.

88. Kaldahl WB, Johnson GK, Patil KD, Kalkwarf KL. Levels of cigarette consumption and response to periodontal therapy. J Periodontol. 1996;67:675-681.

89. Kinane DF, Radvar M. The effect of smoking on mechanical and antimicrobial periodontal therapy. J Periodontol. 1997;68:467-472.

90. Ryder MI, Pons B, Adams D, et al. Effects of smoking on local delivery of controlled-release doxycycline as compared to scaling and root planing. J Clin Periodontol. 1999;26:683-691.

91. Tomar SL, Asma S. Smoking-attributable periodontitis in the United States: Findings from NHANES III. National Health and Nutrition Examination Survey. J Periodontol. 2000;71:743-751.

92. Arbes SJ Jr. Agustsdottir H, Slade GD. Environmental tobacco smoke and periodontal disease in the United States. Am J Public Health. 2001;91:253-257.

93. Yamamoto Y, Nishida N, Tanaka M, et al. Association between passive and active smoking evaluated by salivary cotinine and periodontitis. J Clin Periodontol. 2005;32:1041-1046.

94. Bergstrom J, Preber H. Tobacco use as a risk factor. J Periodontol. 1994;65:545-550.

95. Grossi SG, Zambon JJ, Ho AW, et al. Assessment of risk for periodontal disease. I. Risk indicators for attachment loss. J Periodontol. 1994;65:260-267.

96. Trombelli L, Cho KS, Kim CK, Scapoli C, Scabbia A. Impaired healing response of periodontal furcation defects following flap debridement surgery in smokers. A controlled clinical trial. J Clin Periodontol. 2003;30:81-87.

97. Soder B, Nedlich U, Jin LJ. Longitudinal effect of non-surgical treatment and systemic metronidazole for 1 week in smokers and nonsmokers with refractory periodontitis: A 5-year study. J Periodontol. 1999;70:761-771.

98. Matarazzo F, Figueiredo LC, Cruz SE, Faveri M, Feres M. Clinical and microbiological benefits of systemic metronidazole and amoxicillin in the treatment of smokers with chronic periodontitis: A randomized placebo-controlled study. J Clin Periodontol. 2008;35:885-896.

99. Machion L, Andia DC, Lecio G, et al. Locally delivered doxycycline as an adjunctive therapy to scaling and root planing in the treatment of smokers: A 2-year follow-up. J Periodontol. 2006;77:606-613.

100. Paquette D, Oringer R, Lessem J, et al. Locally delivered minocycline microspheres for the treatment of periodontitis in smokers. J Clin Periodontol. 2003;30:787-794.

101. Tomasi C, Wennstrom JL. Locally delivered doxycycline improves the healing following non-surgical periodontal therapy in smokers. J Clin Periodontol. 2004;31:589-595.

102. Centers for Disease Control. Cigarette Smoking Among Adults United States, 2000. Morb Mortal Wkly Rep Surveill Summ. 2002; 51(29);642-645. Available at: http://www.cdc.gov/mmwr/preview/ mmwrhtml/mm5129a3.htm Accessed on May 17, 2010.

103. Bain CA. Smoking and implant failure - benefits of a smoking cessation protocol. Int J Oral Maxillofac Implants. 1996;11:756-759.

104. Tomar SL, Husten CG, Manley MW. Do dentists and physicians advise tobacco users to quit? J Am Dent Assoc. 1996;127:259-265.

105. Nordland P, Garrett S, Kiger R, et al. The effect of plaque control and root debridement in molar teeth. J Clin Periodontol. 1987;14:231-236.

106. Claffey N, Egelberg J. Clinical characteristics of periodontal sites with probing attachment loss following initial periodontal treatment. J Clin Periodontol. 1994;21:670-679.

107. Waerhaug J. Healing of the dento-epithelial junction following subgingival plaque control. II: As observed on extracted teeth. J Periodontol. 1978;49:119-134.
108. Waerhaug J. Healing of the dento-epithelial junction following subgingival plaque control. I. As observed in human biopsy material. J Periodontol. 1978;49:1-8.

109. Fleischer HC, Mellonig JT, Brayer WK, Gray JL, Barnett JD. Scaling and root planing efficacy in multirooted teeth. J Periodontol. 1989;60:402-409.

110. Brayer WK, Mellonig JT, Dunlap RM, Marinak KW, Carson RE. Scaling and root planing effectiveness: The effect of root surface access and operator experience. J Periodontol. 1989;60: 67-72.

111. Magnusson I, Lindhe J, Yoneyama T, Liljenberg B. Recolonization of a subgingival microbiota following scaling in deep pockets. J Clin Periodontol. 1984;11:193-207.

112. Mousques T, Listgarten MA, Phillips RW. Effect of scaling and root planing on the composition of the human subgingival microbial flora. J Periodontal Res. 1980;15:144-151.

113. Sbordone L, Ramaglia L, Gulletta E, Iacono V. Recolonization of the subgingival microflora after scaling and root planing in human periodontitis. J Periodontol. 1990;61:579-584.

114. Gargiulo AW. Dimensions and relations of the dentogingival junction in humans. J Periodontol. 1961;32:261-267.

115. Vacek JS, Gher ME, Assad DA, Richardson AC, Giambarresi LI. The dimensions of the human dentogingival junction. Int J Periodontics Restorative Dent. 1994;14:154-165.

116. Newcomb GM. The relationship between the location of subgingival crown margins and gingival inflammation. J Periodontol. 1974;45:151-154.

117. Valderhaug J, Birkeland JM. Periodontal conditions in patients 5 years following insertion of fixed prostheses. Pocket depth and loss of attachment. J Oral Rehabil. 1976;3:237-243.

118. Valderhaug J, Ellingsen JE, Jokstad A. Oral hygiene, periodontal conditions and carious lesions in patients treated with dental bridges. A 15-year clinical and radiographic follow-up study. J Clin Periodontol. 1993;20:482-489.

119. Gunay H, Seeger A, Tschernitschek H, Geurtsen W. Placement of the preparation line and periodontal health - a prospective 2-year clinical study. Int J Periodontics Restorative Dent. 2000; 20:171-181.

120. Davies SJ, Gray RJ, Linden GJ, James JA. Occlusal considerations in periodontics. Br Dent J. 2001;191:597-604.

121. Parameter on occlusal traumatism in patients with chronic periodontitis. American Academy of Periodontology. J Periodontol. 2000;71 (5 Suppl):873-875.

122. Fleszar TJ, Knowles JW, Morrison EC, et al. Tooth mobility and periodontal therapy. J Clin Periodontol. 1980;7:495-505.

123. Vollmer WH, Rateitschak KH. Influence of occlusal adjustment by grinding on gingivitis and mobility of traumatized teeth. J Clin Periodontol. 1975;2:113-125.

124. Burgett FG, Ramfjord SP, Nissle RR, et al. A randomized trial of occlusal adjustment in the treatment of periodontitis patients. $J$ Clin Periodontol. 1992;19:381-387.

125. Slots J. Systemic antibiotics in periodontics. J Periodontol. 2004;7 5:1553-1565.

126. Walker CB. The acquistion of antibiotic resistance in the periodontal microflora. Periodontology 2000. 1996;10:79-88.

127. Paster BJ, Boches SK, Galvin JL, et al. Bacterial diversity in human subgingival plaque. J Bacteriol. 2001;183:3370-3383.

128. Sedlacek MJ, Walker C. Antibiotic resistance in an in vitro subgingival biofilm model. Oral Microbiol Immunol. 2007;22:333-339.

129. Shaddox LM, Walker C. Microbial testing in periodontics: Value, limitations and future directions. Periodontol 2000. 2009;50: 25-38.

130. Rooney J, Wade WG, Sprague SV, Newcombe RG, Addy M. Adjunctive effects to non-surgical periodontal therapy of systemic metronidazole and amoyycillin alone and combined. A placebo controlled study. J Clin Periodontol. 2002;29:342-350. 
131. Winkel EG, van Winkelhoff AJ, Barendregt DS, et al. Clinical and microbial effects of initial periodontal therapy in conjunction with amoxicillin and clavulanic acid in patients with adult periodontitis. A randomised double-blind, placebo-controlled study. J Clin Periodontol. 1999;26:461-468.

132. Winkel EG, van Winkelhoff AJ, Timmerman MF, van der Velden U, van der Weijden CA. Amoxicillin plus metronidazole in the treatment of adult periodontitis patients. A double-blind, placebo-controlled study. J Clin Periodontol. 2001;28:296-305.

133. Winkel EG, van Winkelhoff AJ, van der Velden U. Additional clinical and microbiological effects of amoxicillin and metronidazole after initial periodontal therapy. J Clin Periodontol. 1998;25: $857-865$.

134. Walker C, Karpinia K. Rational for the use of antibiotics in periodontics. J Periodontol. 2002;73:1189-1197.

135. Walker C, Karpinia K, Baehni P. Chemotherapeutics: Antibiotics and antimicrobials. Periodontology 2000. 2004;36:146-165.

136. Slots J, Feik D, Rams TE. Prevalence and antimivrobial susceptibility of Enterobacteriaceae, Pseudomonadaceae and Acinobacter in human periodontitis. Oral Microbiol Immunol. 1990;5:149-154.

137. Lowenguth R, Morad V, Gandini L, et al. Effects of local delivery of tetracycline on the progression of juvenile periodontitis. $J$ Dent Res. 1993;72:160. Abstr 451.

138. Vandekerckhove BN, Quirynen M, van Steenberghe D. The use of tetracycline-containing controlled-release fibers in the treatment of refractory periodontitis. J Periodontol. 1997;68:353-361.

139. Rams TE, Slots J. Local delivery of antimicrobial agents in the periodontal pocket. In: Slots J, Rams T, editors. Periodontology 2000. Copenhagen: Munksgaard. 1996:139-159.

140. Machion L, Andia DC, Saito D, et al. Microbiological changes with the use of locally delivered doxycycline in the periodontal treatment of smokers. J Periodontol. 2004;75:1600-1604.
141. Shaddox LM, Andia DC, Casati MZ, et al. Microbiologic changes following administration of locally delivered doxycycline in smokers: A 15-month follow-up. J Periodontol. 2007;78:2143-2149.

142. Machion L, Andia DC, Benatti BB, et al. Locally delivered doxycycline as an adjunctive therapy to scaling and root planing in the treatment of smokers: A clinical study. J Periodontol. 2004;75:464-469.

143. Wennstrom JL, Newman HN, MacNeill SR, et al. Utilisation of locally delivered doxycycline in non-surgical treatment of chronic periodontitis. A comparative multi-centre trial of 2 treatment approaches. J Clin Periodontol. 2001;28:753-761.

144. Golub LM, Ciancio S, Ramamamurthy NS, Leung M, McNamara TF. Low-dose doxycycline therapy: Effect on gingival and crevicular fluid collagenase activity in humans. J Periodontal Res. 1990; 25:321-330.

145. Preshaw PM, Hefti AF, Jepsen S, et al. Subantimicrobial dose doxycycline as adjunctive treatment for periodontitis. A review. J Clin Periodontol. 2004;31:697-707.

146. Cobb CM. Lasers in periodontics: A review of the literature. J Periodontol. 2006;77:545-564.

147. Becker W, Becker BE, Berg LE. Periodontal treatment without maintenance. A retrospective study in 44 patients. J Periodontol. 1984;55:505-509.

148. Wilson TG Jr. Glover ME, Malik AK, Schoen JA, Dorsett D. Tooth loss in maintenance patients in a private periodontal practice. J Periodontol. 1987;58:231-235.

149. Axelsson P, Lindhe J. The significance of maintenance care in the treatment of periodontal disease. J Clin Periodontol. 1981;8:281-294.

150. Mendoza AR, Newcomb GM, Nixon KC. Compliance with supportive periodontal therapy. J Periodontol. 1991;62:731-736.

151. Wilson TG Jr. Glover ME, Schoen J, Baus C, Jacobs T. Compliance with maintenance therapy in a private periodontal practice. $J$ Periodontol. 1984;55:468-473.
Clinical, Cosmetic and Investigational Dentistry

\section{Publish your work in this journal}

Clinical, Cosmetic and Investigational Dentistry is an international, peer-reviewed, open access, online journal focusing on the latest clinical and experimental research in dentistry with specific emphasis on cosmetic interventions. Innovative developments in dental materials, techniques and devices that improve outcomes and patient satisfac-

\section{Dovepress}

tion and preference will be highlighted. The manuscript management system is completely online and includes a very quick and fair peerreview system, which is all easy to use. Visit http://www.dovepress. com/testimonials.php to read real quotes from published authors. 